\title{
Mechanical Properties of Recycled Aggregate Concrete Subjected to Compression Test
}

\author{
Zhang Xianggang ${ }^{1,3}$, Wang Shuren ${ }^{2,3, *}$ and Gao Xiang ${ }^{3}$ \\ ${ }^{1}$ Henan Province Engineering Laboratory of Eco-architecture and the Built Environment, Henan Polytechnic University, Jiaozuo 454003, \\ China \\ ${ }^{2}$ International Joint Research Laboratory of Henan Province for Underground Space Development and Disaster Prevention, Henan \\ Polytechnic University, Jiaozuo 454003, China \\ ${ }^{3}$ School of Civil Engineering, Henan Polytechnic University, Jiaozuo 454003, China
}

Received 5 October 2018; Accepted 22 December 2018

\begin{abstract}
To study the basic mechanical properties of recycled aggregate concrete, four sets of cubic standard test-blocks and four sets of prismatic standard test-blocks were prepared for strength test with the variation parameter of replacement ratio of recycled coarse aggregate. The mechanical indices such as cubic compression strength, axial compression strength, Poisson's ratio, and elastic modulus were investigated by the test. Meanwhile, the replacement ratio influence factor was introduced to establish the conversion relationship of the strength indices, as well as the calculation formula of elastic modulus. Results show that the strength trend with the middle large and two ends small can be generally refined with the increase of replacement ratio. The Poisson's ratio and elastic modulus of the recycled aggregate concrete vary less within the allowable range of engineering error. The established conversion relationship of strength indices and the calculation formula of elastic modulus are simple and practical with the large fitting precision. The conclusions obtained in the study are of important reference value to direct similar engineering practice.
\end{abstract}

Keywords: Recycled aggregate concrete, Elastic modulus, Poisson's ratio, Compression strength

\section{Introduction}

During the construction of civil engineering, waste concrete is a focus among ecological environment issues [1]. With the rapid increase in the amount of waste concrete and the tight supply of natural aggregates, the recycling and utilization of waste concrete is a problem facing research and engineering personnel based on the green concept of sustainable development for construction industry [2]. How to dispose of waste concrete scientifically and reasonably has become a hot spot in the field of concrete research [3-5].

Recently, recycled aggregate concrete (RAC) technology is one of the most effective ways. The construction waste can be recycled, crushed, washed and graded, and then mixed to form recycled aggregates with a certain proportion and grading. After that, the recycled aggregates are used to replace partially or completely natural aggregates, such as sand and gravel. Finally, a mixture of cement and water is added to prepare a new concrete named RAC [6-8]. On the one hand, RAC can solve the problem of disposal for waste concrete. On the other hand, natural aggregate is replaced with construction waste in RAC, which can reduce the consumption of natural aggregate and relieve the supply pressure of natural aggregates. The social, economic and environmental benefits of RAC are obvious and it has been considered as green concrete that can realize sustainable development of construction resources [9-11]. So it is very important to study the basic mechanical properties of RAC.

*E-mail address: w_sr88@163.com

ISSN: $1791-2377$ @ 2018 Eastern Macedonia and Thrace Institute of Technology. All rights reserved.

doi:10.25103/jestr.116.04

\section{State of the art}

Similar to ordinary concrete, RAC is also a kind of local material. Due to variety of sources for recycled aggregates, the treatment of recycled aggregates and the preparation of RAC are varied. Ma used organic pretreatment methods to modify and reinforce coarse aggregates recovered from rural construction waste, which provided a new way for the reinforcement of recycled coarse aggregates [12]. Li et al. studied the crushing and screening process of recycled aggregates from waste concrete, they found that the recycling and reuse of construction waste was an effective solution to construction waste and the shortage of natural aggregates [13]. Cabral et al. used concrete, ceramic tiles, and mortar as the main source of recycled coarse and fine aggregates to prepare RAC. They found that recycled coarse aggregates had a greater impact on the performance of RAC than recycled fine aggregates [14]. Wagih et al. fractured and graded the gravel concrete at different demolition sites and landfills around Cairo, Egypt, and studied the mechanical and physical properties of recycled coarse aggregate. They found that gravel concrete can be converted into the useful recycled aggregates [15]. Although the source of construction waste is different, recycled aggregates that meet the requirements of RAC can be produced by way of reasonable aggregate treatment and concrete preparation.

In terms of mechanical properties, the difference between RAC and ordinary concrete is mainly caused by the source of aggregate. Most of the aggregates in RAC are recycled aggregates, while the aggregates in ordinary concrete are natural aggregates. Medina et al. studied the possibility of replacing natural coarse aggregate with recycled ceramic coarse aggregate, and they found that the 
compressive strength of RAC increased with the increase of the replacement ratio of recycled ceramic coarse aggregate [16]. Zhou et al. studied the effects of recycled gravel aggregate and recycled pebble aggregate on the mechanical properties of RAC, they found that the RAC with recycled gravel aggregate had lower compressive strength than RAC with recycled pebble aggregate, while the toughness was reversed [17]. Guo et al. studied the compressive properties of concrete blocks containing recycled aggregate of concrete and they found that the compressive properties of RAC blocks were similar to those of ordinary concrete after incorporating recycled aggregates [18]. Sun and Xiao studied the strength and elastic modulus of RAC at different recycled aggregate dosages and ages of concrete, they found that the strength developing rule of RAC was similar to that of ordinary concrete with age growing, and the strength and modulus of elasticity for RAC decreased with the increase of recycled aggregate dosage [19]. Tabsh and Abdelfatah believed that the compressive strength and splitting tensile strength of RAC depended on the mixing ratio [20]. Some research results showed that the compressive strength and elastic modulus of RAC were lower than ordinary concrete [21-23]. In summary, despite the different sources of recycled aggregates, the mechanical properties of concrete changed significantly after the incorporation of recycled aggregates into ordinary concrete. In the past, most of the construction wastes with shorter service time were used as the source of recycled aggregates. Due to the short service time, the source of aggregates may be less affected by harsh environments such as air, high temperature, wind and snow, and the performance of building materials in itself may not deteriorate. Moreover, the reliability of the structure was not greatly reduced.

Different from the previous research, this study took the pre-stressed concrete poles that had been exposed to the harsh outdoor environment and in service for 50 years as the source of recycled coarse aggregates. The cubic compression strength, axial compression strength, Poisson's ratio, elastic modulus and other mechanical performance of RAC were comprehensively studied. The formulas for strength index conversion relationship and elastic modulus calculation were established. The purpose was to expand the research content of RAC and provide a reference for the further research and application of RAC structure.
The rest of this study is organized as follows: Section 3 describes the test design. Section 4 quantitatively analyzes the changes of compressive strength, elastic modulus and Poisson's ratio. Section 5 provides the relevant conclusions.

\section{Methodology}

\subsection{Test materials}

The materials used in the test were natural and recycled coarse aggregate, P.O 42.5R grade cement, urban tap water and natural river sand. The recycled coarse aggregate was obtained by mechanically breaking the prestressed concrete poles served in a project commissioned by the China Electric Power Research Institute. The recycled and natural coarse aggregate were sieved by the same set of screen with the maximum particle size of $20 \mathrm{~mm}$, and all the coarse aggregates were continuous grading gravel. The recycled coarse aggregate obtained by the crushing was washed several times until the control requirement for the mud content of the recycled coarse aggregate was reached, and after drying and reaching the required moisture content, it was used in preparing RAC.

\subsection{Mix ratio and physical properties for RAC}

The total levels forreplacement ratio of recycled coarse aggregate including $0 \%, 30 \%, 70 \%$ and $100 \%$ were determined with the control replacement ratio of $0 \%$. The design strength of RAC was C40. For the RAC at different replacement ratios of recycled coarse aggregate, the mass composition of cement and sand was kept unchanged, and the mass composition ratio between recycled coarse aggregate and recycled coarse aggregate was changed under the condition that the total mass of coarse aggregate was equal. The mix ratio of RAC was shown in Table 1.

According to the current national standard 'Pebble and crushed stone for construction' (China GB/T14685-2011), the physical properties for natural coarse aggregate and recycled aggregate coarse aggregate were tested. The measured physical properties of both the coarse aggregates were shown in Table 2.

Table. 1. Mix ratio of RAC

\begin{tabular}{c|c|c|c|c|c|c|c}
\hline $\begin{array}{c}\text { Replacement } \\
\text { ratio (\%) }\end{array}$ & $\begin{array}{c}\text { Sand ratio } \\
(\%)\end{array}$ & $\begin{array}{c}\text { Water-binder } \\
\text { ratio }\end{array}$ & $\begin{array}{c}\text { Cement } \\
(\mathbf{k g})\end{array}$ & $\begin{array}{c}\text { Net water } \\
\text { content (kg) }\end{array}$ & $\begin{array}{c}\text { Natural oarse } \\
\text { aggregate (kg) }\end{array}$ & $\begin{array}{c}\text { Recycled coarse } \\
\text { aggregate (kg) }\end{array}$ & $\begin{array}{c}\text { Sand } \\
(\mathbf{k g})\end{array}$ \\
\hline 0 & & & & & 1115.2 & 0.0 & \\
30 & & & & & 780.6 & 334.6 & \\
70 & 33.6 & 0.47 & 435.7 & 204.8 & 334.6 & 780.6 & 564.3 \\
100 & & & & & 0.0 & 1115.2 & \\
\hline
\end{tabular}

Table. 2. Basic physical properties of coarse aggregates

\begin{tabular}{c|c|c|c|c|c}
\hline $\begin{array}{c}\text { Coarse aggregate } \\
\text { type }\end{array}$ & $\begin{array}{c}\text { Particle size } \\
(\mathbf{m m})\end{array}$ & $\begin{array}{c}\text { Bulk density } \\
\left(\mathbf{k g} / \mathbf{m}^{\mathbf{3}}\right)\end{array}$ & $\begin{array}{c}\text { Apparent density } \\
\left(\mathbf{k g} / \mathbf{m}^{\mathbf{3}}\right)\end{array}$ & $\begin{array}{c}\text { Moisture content } \\
(\mathbf{\%})\end{array}$ & $\begin{array}{c}\text { Water absorption } \\
(\mathbf{\%})\end{array}$ \\
\cline { 1 - 5 } Natural & \multirow{2}{*}{$5-20$} & 1435 & 2722 & 0.00 & 0.05 \\
\cline { 1 - 5 } Recycled & & 1270 & 2655 & 1.82 & 3.16 \\
\cline { 3 - 6 } & & &
\end{tabular}

It could be summarized from Table 2 that the bulk density andapparent density of the recycled coarse gravelaggregate were smaller than those of the natural coarse gravel-aggregate, while the moisture content and water absorption were much larger than the natural coarse gravelaggregate. It was mainly attributed to the composition of the material and the internal microstructure. A large amount of hardened cement mortar was attached to the surface of the recycled coarse aggregate, making the surface rough and the porosity high. Moreover, during the mechanical crushing process, more closed micro-cracks or cracks were generated inside the recycled coarse aggregate. However, the natural coarse aggregate had a single composition and the internal microstructure was dense. 


\subsection{Test methods}

For each replacement ratio of recycled coarse aggregate, three $150 \mathrm{~mm} \times 150 \mathrm{~mm} \times 150 \mathrm{~mm}$ cube standard testblocks and three $150 \mathrm{~mm} \times 150 \mathrm{~mm} \times 300 \mathrm{~mm}$ prismatic standard test-blocks were manufactured for normal curing in concrete curing box. After the completion of the curing, the test of the strength and deformation performance of the testblocks was carried out according to the current 'Standard for test method of mechanical properties on ordinary concrete' (China GB50081-2002). The test was completed on RMT201 mechanics test machine of rock and concrete.

\section{Results Analysis and Discussion}

\subsection{Compressive failure mode}

The failure modes for the cube and prismatic test-blocks were shown in Figs. 1 and 2, respectively. It could be illustrated that for the cube compression failure, when the replacement ratio was $0 \%$ and $100 \%$, both the failure modes of the test-block was more serious than other replacement ratios. For the axial compression failure, when the replacement ratio was $30 \%$ and $70 \%$, the crack was dense and uniform, and the mechanical performance of the testblock was better than other replacement ratios.

\subsection{Compressive strength}

The measured cubic and prismatic compression strength are shown in Table 3 , where the $f_{\mathrm{cu}}$ and $f_{\mathrm{c}}$ represent the cubic compression strength and the axial compression strength, respectively. $\gamma$ stands for the replacement ratio of recycled coarse aggregate.

It can be summarized from Table 3 that the strength goes up with increase of the replacement ratio. However, when the replacement ratio is $100 \%$, the strength decreases, especially the cubic compression strength. Whether for the cubic compression strength or the axial compression strength, the overall trend with the middle large and the two ends small can be refined. The reason is mainly related to the mechanism influence of recycled coarse aggregate on RAC compressive strength.

On the one hand, during the process of mechanical crushing, there are many micro-cracks in the recycled coarse aggregate, and more original damage is accumulated inside the aggregate. Due to the quality deterioration of the recycled coarse aggregate, the compressive strength of RAC is able to be inevitably weakened. On the other hand, due to the existence of many micro-cracks in the recycled coarse aggregate, the water absorption of the recycled coarse aggregate is significantly higher than that of the natural coarse aggregate. Meanwhile, the water absorbed into the recycled coarse aggregate gradually increases with the increase of the replacement ratio of recycled coarse aggregate, whereas the additional absorbed water does not participate in the hydration of cement, therefore, the actual water-binder ratio will be reduced, resulting in the improvement of compressive strength of RAC. Both the above factors interact with each other, the greater the replacement ratio of the recycled coarse aggregate, the more internal damage of the material, the greater the reduction about RAC compressive strength. However, the actual water-binder ratio become lower, causing the greater increase about RAC compressive strength. At a certain replacement ratio, the two factors will be optimally configured to make the RAC compressive strength optimal. Obviously, this replacement ratio is the optimal one.

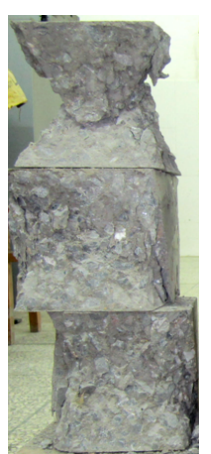

(a) $0 \%$

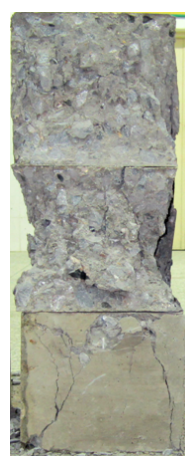

(b) $30 \%$

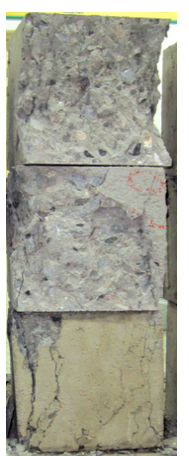

(c) $70 \%$

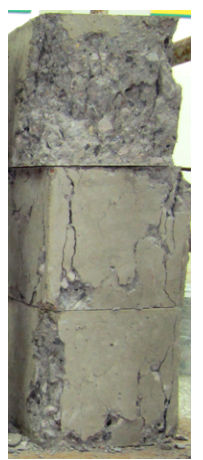

(d) $100 \%$
Fig. 1. The failure mode of the cube test

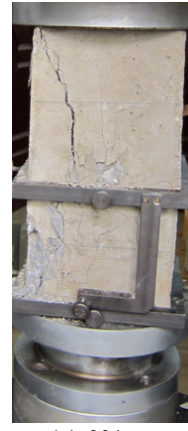

(a) $0 \%$

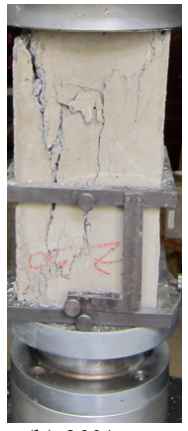

(b) $30 \%$

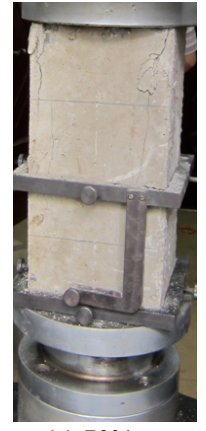

(c) $70 \%$

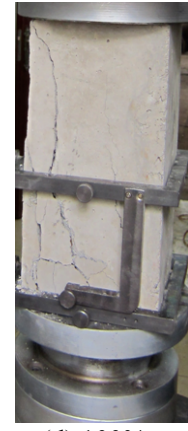

(d) $100 \%$
Fig. 2. The failure mode of the prismatic test block

Table 3. Measured strength indices of RAC

\begin{tabular}{c|c|c|c}
\hline$\gamma(\%)$ & $f_{\mathrm{c}} / f_{\mathrm{cu}}$ & $f_{\mathrm{cu}}(\mathrm{MPa})$ & $f_{\mathrm{c}}(\mathrm{MPa})$ \\
\hline 0 & 0.79 & 46.8 & 37.1 \\
30 & 0.73 & 50.8 & 36.9 \\
70 & 0.71 & 53.8 & 38.2 \\
100 & 0.73 & 50.1 & 36.8 \\
\hline
\end{tabular}

Due to the limitations of the test conditions, the replacement ratio in this studywas only $0 \%, 30 \%, 70 \%$ and $100 \%$. Based on the experimental results, the RAC compressive strength was slightly improved when the replacementratiowas $70 \%$. The author proposed to design a variety of replacement ratios and conducted a series of related experiments to reveal the influence rule of the replacement ratio on the compressive strength, and confirmed the optimal replacement ratio about the strength.

\subsubsection{Cube compressive strength at different replacement ratios}

The dimensionless curve of the cube compressive strength at different replacement ratios is shown in Fig. 3, in which, $f_{\text {cu }}$ represents the cube compressive strength at different replacementratios, and $f_{\mathrm{cu}, 0}$ represents the cube compressive strength at a replacementratio of $0 \%$. It can be indicated from Fig. 3 that the cube compressive strength at different replacementratios is not the same, but shows a certain regularity. Based on the developingtrend of measured data, a mathematical expression of the cubic functionis proposed as follows.

$$
\frac{f_{\mathrm{cu}}}{f_{\mathrm{cu}, 0}}=A \gamma^{3}+B \gamma^{2}+C \gamma+D
$$

where $A, B, C$ and $D$ respectively represent control parameters, which are described from the test data fitted based on the least square method. The values of control 
parameters are $-0.4274,0.2493,0.2486$ and 1.0000 , respectively, and the fitting precision is 1.0 .

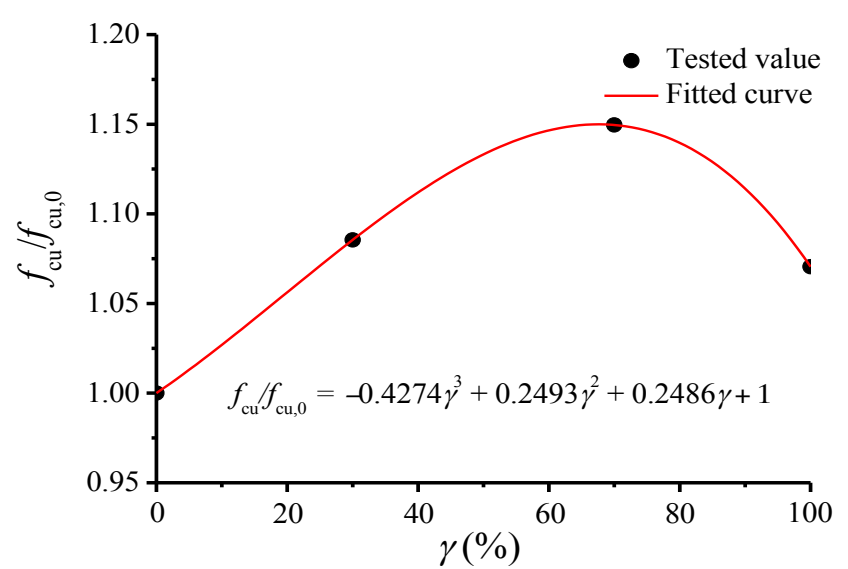

Fig. 3. Cube compressive strength at different replacement ratios

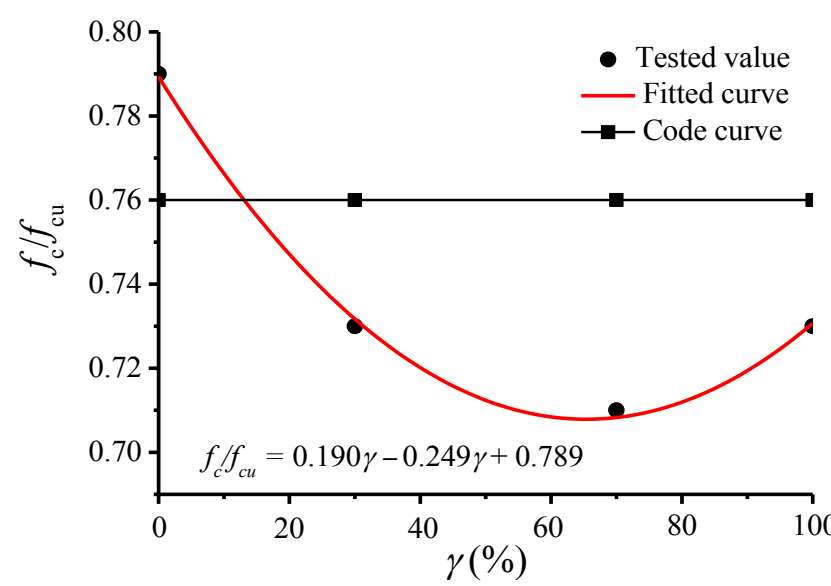

Fig. 4. The curvebetween $f_{\mathrm{c}} / f_{\mathrm{cu}}$ and $\gamma$

\subsubsection{Conversion of compressive strength indices}

The relationship curve between cubic compression strength and axial compression strength at different replacement ratios is shown in Fig. 4. It can be presented from Fig. 4 that $f_{\mathrm{c}} / f_{\mathrm{cu}}$ reached the maximum 0.79 when the replacement ratio is $0 \%$. With the replacement ratio increasing, $f_{\mathrm{c}} / f_{\mathrm{cu}}$ decreased overall, with the minimum of 0.71. In Code for design of concrete structures (China GB50010-2010), it is declaredthat for ordinary concreteof $\mathrm{C} 40, f_{\mathrm{c}}=0.76 f_{\mathrm{cu}}$. As a result, the current design code is not suitable for the design requirement of RAC. Based on the trend of the quadratic function for measured data, the modified coefficient $(1+\gamma T)$ is introduced into the relationship of $f_{\mathrm{c}} / f_{\mathrm{cu}}$ when the replacement ratio is $0 \%$, as shown in Eqs. (2) to (3):

$\frac{f_{\mathrm{c}}}{f_{\mathrm{cu}}}=0.79(1+\gamma T)$

where $T$ represents a modified equation related to the replacementratio. The expression is as follows:

$$
T=\gamma A+\frac{B}{\gamma}+C
$$

where $A, B$ and $C$ are all the control parameters. The equation is incorporated into Eq. (2) and the following equation can be drawn.

$\frac{f_{\mathrm{c}}}{f_{\mathrm{cu}}}=0.79 A \gamma^{2}+0.79 C \gamma+0.79 B+0.79$

Based on the principle of the least square method, the control parameters are obtained by fitting the experimental data which are $0.241,0.000$ and -0.315 , respectively, as shown in Eq. (5), and the fitting precisionis 0.994.

$$
\frac{f_{\mathrm{c}}}{f_{\mathrm{cu}}}=0.190 \gamma^{2}-0.249 \gamma+0.789
$$

\subsection{Poisson's ratio}

The Poisson's ratio $v_{\mathrm{c}}$ of RAC at different stress levels can be measured by transverse and longitudinal strain gauges on one side of the prismatic standard test-block, as shown in Table 4 , where $f_{\mathrm{c}}$ is taken as the design value.

As observed from Table 4, the Poisson's ratio of RAC increases slightly with the increase of RAC stress level. However, at the same stress level, the Poisson's ratio of RAC always varied less, regardless of the variation for replacement ratio of recycled coarse aggregate. Therefore, it is shown that the transverse deformation performance of RAC varied less with the increase of the replacement ratio of recycled coarse aggregate, and the amplitude of variation remains within $5 \%$.

Table 4. Measured deformation performance of RAC

\begin{tabular}{c|c|c|c|c|c}
\hline \multirow{2}{*}{$\gamma(\%)$} & $E_{\mathrm{c}}$ & \multicolumn{4}{|c}{$\boldsymbol{v}_{\mathrm{c}}$} \\
\cline { 3 - 6 } & $(\mathrm{GPa})$ & $0.2 f_{\mathrm{c}}$ & $0.4 f_{\mathrm{c}}$ & $0.6 f_{\mathrm{c}}$ & $0.8 f_{\mathrm{c}}$ \\
\hline 0 & 37.2 & 0.16 & 0.19 & 0.20 & 0.21 \\
30 & 38.4 & 0.17 & 0.19 & 0.19 & 0.22 \\
70 & 38.9 & 0.18 & 0.18 & 0.21 & 0.21 \\
100 & 36.7 & 0.18 & 0.19 & 0.20 & 0.21 \\
\hline
\end{tabular}

\subsection{Elastic modulus}

According to the Standard for Test Method of Mechanical Properties on Ordinary Concrete (China GB50081-2002), the elastic modulus of RAC can be measured. The formula for calculating the elastic modulus is shown in Eq. (6).

$$
E_{\mathrm{c}}=\frac{F_{\mathrm{a}}-F_{0}}{A} \times \frac{L}{4_{\mathrm{n}}}
$$

where $E_{\mathrm{c}}$ is the elastic modulus of concrete $(\mathrm{MPa}), F_{\mathrm{a}}$ is the vertical load $(\mathrm{N})$ when the stress is applied to the $1 / 3$ axial compression strength, $F_{0}$ is the initial load $(\mathrm{N})$ when the stress is applied to $0.5 \mathrm{MPa}, L$ is measuring scale distance $(150 \mathrm{~mm}), \Delta_{\mathrm{n}}$ is the average value $\left(\Delta_{\mathrm{n}}=\Delta_{\mathrm{a}}-\Delta_{0}, \mathrm{~mm}\right)$ of deformation on both sides of the test-block when the load is applied from $F_{0}$ to $F_{\mathrm{a}}$ at the last time, $\Delta_{\mathrm{a}}$ is the average value $(\mathrm{mm})$ of deformation on both sides of the test-block 
when the load is applied to $F_{\mathrm{a}}, \Delta_{0}$ is the average value $(\mathrm{mm})$ of deformation on both sides of the test-block when the load is applied to $F_{0}$.

The elastic modulus measured by the Eq. (6) is shown in Table 4. It can be summarized from Table 4 that as replacement ratio of coarse aggregate varies from $0 \%$ to $100 \%$, the variation amplitude of elastic modulus for RAC is $3.23 \%, 1.30 \%$ and $-5.66 \%$, respectively, and the variation amplitude is within the acceptable range of engineering error, resulting that with the replacement of recycled coarse aggregate increasing, the longitudinal deformation performance of the RAC varies less.

Elastic modulus is an important index of deformation performance for materials. Although scholars have carried out related experiments on the elastic modulus of RAC [9$11]$, there is a lack of mathematical expressions about the elastic modulus. In Code for Design of Concrete Structures (China GB50010-2010), it is declaredthat for ordinary concrete:

$$
E_{\mathrm{c}}=\frac{10^{5}}{2.2+\frac{34.7}{f_{\mathrm{cu}}}}
$$

The test-measured data was taken into the above formula to calculate the value $E_{\mathrm{c}}^{\mathrm{c}}$ of elastic modulus for RAC. The relationship curve of elastic modulus between the tested value $E_{\mathrm{c}}^{\mathrm{t}}$ and the calculated value $E_{\mathrm{c}}^{\mathrm{c}}$ at different replacement ratios is shown in Fig. 5.

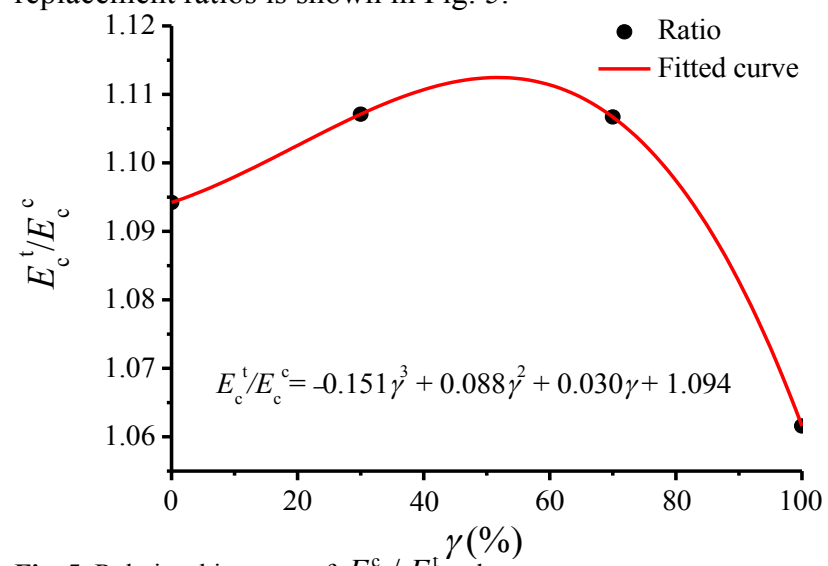

Fig. 5. Relationship curve of $E_{\mathrm{c}}^{\mathrm{c}} / E_{\mathrm{c}}^{\mathrm{t}}$ and $\gamma$

It can be illustrated from Fig. 5 that the $E_{\mathrm{c}}^{\mathrm{c}}$ calculated by the formula in China GB50010-2010 was generally larger than $E_{\mathrm{c}}^{\mathrm{t}}$. Obviously, the current codewas no longer applicable to the calculation for elastic modulus of RAC. However, there was a trend of cubic function between $E_{\mathrm{c}}^{\mathrm{c}} / E_{\mathrm{c}}^{\mathrm{t}}$ and $\gamma$. Therefore, the current code formula can be modified by a mathematical expressionof cubic function, as shown in Eq. (8):

$$
E_{\mathrm{c}}=\frac{10^{5}}{2.2+\frac{34.7}{f_{\mathrm{cu}}}} \times\left(A \gamma^{3}+B \gamma^{2}+C \gamma+D\right)
$$

where $A, B$ and $C$ are control parameters. Based on the correlated data including $E_{\mathrm{c}}^{\mathrm{c}} / E_{\mathrm{c}}^{\mathrm{t}}$ and $\gamma$, the control parameters can be fitted by the principle of the least square method, that is, $A=-0.151, B=0.088, C=0.030$ and $D=1.094$ as shown in Eq. (9), and the fitting precisionis 1.000.

$$
E_{\mathrm{c}}=\frac{10^{5}}{2.2+\frac{34.7}{f_{\mathrm{cu}}}} \times\left(-0.151 \gamma^{3}+0.088 \gamma^{2}+0.030 \gamma+1.094\right)
$$

\section{Conclusions}

Based on the test for the strength and deformation performance of recycled aggregate concrete, the main conclusions are as follows:

(1) The strength increases with the increase of replacement ratio, while the strength decreases, especially the cubic compression strength, when the replacement ratio is $100 \%$. In general, the overall trendwith the middle large and the two ends small can be refined.

(2) The influence factor of replacement ratio is introduced to establish the conversion relationship between cubic and axial compression strength of RAC, as well as the calculation formula of elastic modulus.

(3) With the increase of the replacement ratio, the transverse and longitudinal deformation performance of RAC varied less, and the variation amplitudeis within the allowable range of engineering error.

The grade of mix ratio for RAC is C40, and the established strength and elastic modulus expressions are related to the strength grade. Whether the RAC of other strength grades are applicable to the formulas is subject to further experimental verification and theoretical analysis.

\section{Acknowledgements}

This work was financially supported by the NationalNatural Science Foundation of China (51774112, 51474188, 51074140), the Doctoral Fund of HenanPolytechnic University (B2015-67), Taihang Scholars Program, the Science and Technology Breakthrough Project of Henan Province (172102210285), the Fundamental Research Funds for the Universities of Henan Province (NSFRF170921), the Safe Production Project of Key Technology for Major Accident Prevention and Control (Henan-0006-2016AQ).

This is an Open Access article distributed under the terms of the Creative Commons Attribution Licence

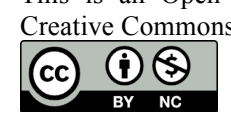

\section{References}

1. Zhu, X. Y., Chen, X. D., Shen, N., Tian, H. X., Fan, X. Q., Lu, J., "Mechanical properties of pervious concrete with recycled aggregate". Computers and Concrete, 21(6), 2018, pp. 623-635.

2. Pedro, D., de Brito, J. D., Evangelista, L., "Influence of the use of recycled concrete aggregates from different sources on structural concrete". Construction and Building Materials, 71, 2014, pp. 141151.
3. Zhang, X. G., Kuang, X. M., Yang, J. H., Wang, S. R., "Experimental study on mechanical properties of lightweight concrete with shale aggregate replaced partially by nature sand". Electronic Journal of Structural Engineering, 17(1), 2017, pp.8594. 
4. Behera, M., Bhattacharyya, S. K., Minocha, A. K., Deoliya, R., Maiti, S., "Recycled aggregate from C \& D waste \& its use in concrete-A break through towards sustainability in construction sector: A review". Construction and Building Materials, 68, 2014, pp.501516.

5. Belin, P., Habert, G., Thiery, M., Roussel, N., "Cement paste content and water absorption of recycled concrete coarse aggregates". Materials and Structures, 47(9), 2014, pp. 1451-1465.

6. Li, X., "Recycling and reuse of waste concrete in China: Part I. Material behaviour of recycled aggregate concrete". Resources Conservation and Recycling, 53(1), 2008, pp. 36-44.

7. Chi, S. P., Chan, D., "Paving blocks made with recycled concrete aggregate and crushed clay brick". Construction and Building Materials, 20 (8), 2006, pp. 569-577.

8. Yang, J., Du, Q., Bao, Y., "Concrete with recycled concrete aggregate and crushed clay bricks". Construction and Building Materials, 25(4), 2011, pp. 1935-1945.

9. Suhendro, B., "Toward Green Concrete for Better Sustainable Environment". Procedia Engineering, 95, 2014, pp. 305-320.

10. Wang, S.R., Xiao, H. G., Hagan, P., Zou, Z. S., "Mechanical behavior of fully-grouted bolt in jointed rocks subjected to double shear tests". Dyna, 92(3), 2017, pp.314-320.

11. Mo, K. H., Alengaram, U. J., Jumaat, M. Z., Yap, S. P., Lee, S. C., "Green concrete partially comprised of farming waste residues: a review". Journal of Cleaner Production, 117, 2016, pp.122-138.

12. Ma, X., "Optimization of organic method for pretreatment of coarse aggregate recycled from rural construction waste". Concrete, 30(10), 2013, pp.104-107.

13. Li, Z. S., Xie, L. H., Luo, J. Y., "The Mechanical properties of recycled aggregate concrete". Advanced Materials Research, 671674, 2013, pp. 1852-1855.

14. Cabral, A. E. B., Schalch, V., Dal Molin, D. C. C., Ribeiro, J. L. D., "Mechanical properties modeling of recycled aggregate concrete". Construction and Building Materials, 24(4), 2010, pp. 421-430.
15. Wagih, A. M., El-Karmoty, H. Z., Ebid, M., Okba, S. H., "Recycled construction and demolition concrete waste as aggregate for structural concrete". HBRC Journal, 9(3), 2013, pp. 193-200.

16. Medina, C., Frías, M., de Rojas, M. I. S., "Microstructure and properties of recycled concretes using ceramic sanitary ware industry waste as coarse aggregate". Construction and Building Materials, 31(6), 2012, pp. 112-118.

17. Zhou, C. H., Chen, Z. P., "Mechanical properties of recycled concrete made with different types of coarse aggregate". Construction and Building Materials, 134, 2017, pp. 497-506.

18. Guo, Z. G., Tu, A., Chen, C., Lehman, D. E., "Mechanical properties, durability, and life-cycle assessment of concrete building blocks incorporating recycled concrete aggregates". Journal of Cleaner Production, 199, 2018, pp.136-149.

19. Sun, Y. D., Xiao, X., "Experiment research on basic mechanic property of recycled concrete with different ratio of recycled aggregate". Advanced Materials Research, 250-253, 2011, pp. 994-1000.

20. Tabsh, S. W., Abdelfatah, A. S., "Influence of recycled concrete aggregates on strength properties of concrete". Construction and Building Materials, 23(2), 2009, pp. 1163-1167.

21. Xiao, J. Z., Li, J. B., Zhang, C., "On relationships between the mechanical properties of recycled aggregate concrete: An overview". Materials and Structures, 39(6), 2006, pp.655-664.

22. Rahal, K., "Mechanical properties of concrete with recycled coarse aggregate". Building and Environment, 42(1), 2007, pp.407-415.

23. Kou, S. C., Poon, C. S., "Mechanical properties of 5-year-old concrete prepared with recycled aggregates obtained from three different sources". Magazine of Concrete Research, 60(1), 2008, pp. 57-64. 